\title{
Del Castell de Castalla al Conjunt Patrimonial del Castell de Castalla: un nuevo enfoque en la gestión del patrimonio cultural valenciano
}

\author{
Juan Antonio Mira Rico , Màrius Bevià i Garciab, José Ramón Ortega Pérez \\ aServei Municipal de Patrimoni Cultural de Castalla, Castalla, España, mirarico@hotmail.com, ${ }^{\mathrm{b}}$ Arquitecto, Sant \\ Joan d'Alacant, España, mariusbg@gmail.com, 'ARPA Patrimonio S.L., Villena, Sant Vicent del Raspeig, España, \\ arpaoscu@yahoo.es
}

\begin{abstract}
The present administration of Cultural Heritage demands its comprehensive management line according to its environment, in many occasions with an important. An example of this found in Castalla (Alicante). Its castle was san, until 2009, as the only cultural asset of a hill which, in fact, many other cultural and natural riches, although they were badly known, preserved and spread. Since then, a new perspective base don managing, not only the fortification but also every cultural and natural heritage on the hill, was taken. From that moment, the Castalla Castle Heritage Site was defined. An interdisciplinary management team was set up and a strategy of intervention, which has already given some results, was designed based on investigation, preservation, restoration, didactics and promotion.
\end{abstract}

Keywords: Castalla Castle, cultural and natural heritage, management, Castalla Castle Heritage Site

\section{Introducción ${ }^{1}$}

Por Conjunt Patrimonial del Castell de Castalla (en adelante CPCC) se entiende la agrupación de bienes culturales (materiales e inmateriales), y naturales, con unos valores históricos, medioambientales y patrimoniales comunes, localizados $y / o$ que se celebran en el promontorio del Castell de Castalla.

Dicha denominación es el fruto de un proceso de trabajo y reflexión cuyo origen radica en la investigación sobre la gestión del patrimonio cultural de Castalla desarrollada por Juan Antonio Mira Rico, en el seno de la Universidad de Alicante, entre los años 2003-2005 (Mira, 2005).

Todo el trabajo realizado fue fundamental para conocer el patrimonio cultural de Castalla y, particularmente, el situado en el cerro del castillo. En este sentido, su gestación supuso el acercamiento a la fortificación, en la cual se ejecutaba la intervención arquitectónica (20032006), bajo la dirección del arquitecto Màrius Bevià i Garcia.

Pero también sirvió para tomar conciencia de la realidad patrimonial existente en el cerro del castillo. Una realidad que estaba relacionada estrechamente entre sí, iba más allá de la propia fortificación y había que tener en cuenta a la hora de administrar correctamente el castillo; pero de la cual, paradójicamente, no se sabía nada porque la fortificación había acaparado, tradicionalmente, toda la atención de la sociedad, algo lógico, pues además de su importancia histórica y patrimonial, es el emblema de la localidad. 


\section{1. ¿Qué bienes lo forman?}

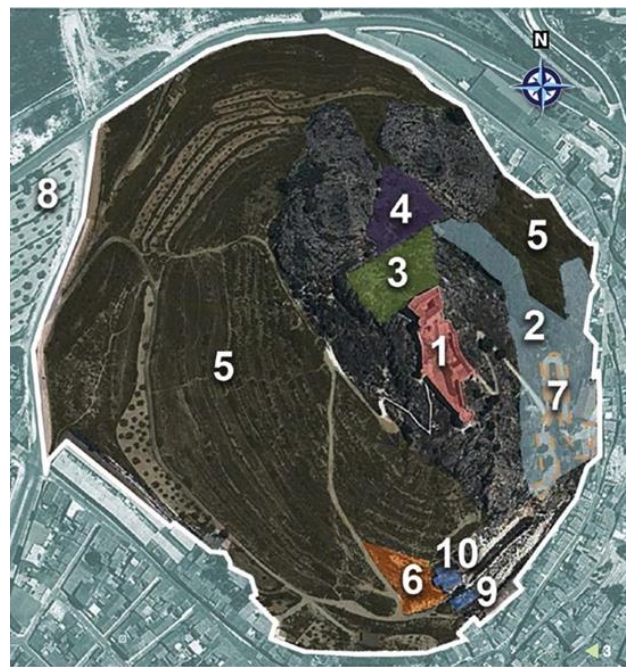

Fig. 1- Conjunt Patrimonial del Castell de Castalla (Juan Antonio Mira Rico y Daniel Liñana Torres, 2014).

Tras una primera propuesta de caracterización en 2006, y posteriores actualizaciones en 2009 y 2012, en la actualidad el CPCC está formado por los siguientes bienes culturales y naturales: Castell de Castalla (1) (Menéndez, Bevià, Mira y Ortega, 2010), posible albacar (o albacara en castellano) (2) (Mira y Ortega, 2010), posible necrópolis del Fossar Vell (3) (Ortega y Esquembre, 2010: 90), vila de Castalla (4) (Bevià, Camarero y Jiménez, 1985; Mira y Ortega, 2010; Ortega y Esquembre, 2010; Torró, 1988-1989; Vidal y Navarro, 1985), márgenes y bancales de cultivo tradicionales (5) (Mira, en prensa), yacimiento arqueológico del Dipòsit Vell (6) (Cerdà, 1994), Vías Crucis (7) (http://www.cult.gva.es/dgpa/etnologia/Detalles _etnologia.asp?IdFicha=2792http://www.cult.gv a.es/dgpa/etnologia/Detalles_etnologia.asp?IdFic ha=2793), escenario bélico de las batallas de Castalla (González, 2010), depósito de agua de 1928 (9) (Cerdà i Espinosa, 2010), depósito de agua de 1960 (10) (Cerdà i Espinosa, 2010), Semana Santa (Ariño, Gil-Hernández, Melis, 1999), Fiestas de moros y cristianos (Ariño, 1988, Ariño y Alcaraz, 2001; González, 2004), toques manuales de la campana María (Llop, 2011), 224 especies de flora pertenecientes a 59 familias botánicas y 37 especies de fauna vertebrada (Mira y Liñana, 2014).

Sin entrar en detalle en cada uno de ellos, de los cuales podrá encontrarse información más detallada en un trabajo de próxima publicación (Mira, en prensa) y en la bibliografía citada; claramente se aprecia su diversidad y riqueza patrimonial.

En una extensión de 11 ha, existe un patrimonio cultural que abarca desde la Prehistoria (II milenio a.C.) hasta la actualidad. Una etapa histórica dilatada en la cual destaca, por ejemplo, la representada por el castillo durante la Edad Media como enclave de frontera entre las coronas de Aragón y Castilla. Igualmente resalta su importancia como escenario de alguna de las fiestas más importantes del calendario festivo de Castalla, caso de las Fiestas de moros y cristianos y la Semana Santa; o como punto estratégico durante los dos enfrentamientos bélicos ocurridos durante la Guerra de la Independencia contra los invasores franceses, el 12 de julio de 1812 y el 13 de abril de 1813 . Por último, tampoco pueden olvidarse sus aspectos naturales. El CPCC se encuentra estrechamente relacionado con el Paisaje Protegido de la Serra del Maigmó y Serra del $\mathrm{Sit}^{2}$. No en vano, el macizo rocoso forma parte, desde el punto de vista geológico de la Sierra del Maigmó (Marco, 1987: 17, fig. 1), aunque por causas desconocidas quedó fuera de los límites del paisaje protegido.

Por lo tanto, además de compartir rasgos geológicos también comparten una flora y fauna, en muchos casos, comunes. Sirva de ejemplo el siguiente dato: las 31 especies faunísticas localizadas en el CPCC, también se encuentran presentes en el paisaje protegido. Y lo mismo ocurre con 8 de las especies de flora documentadas.

A nivel de fauna destaca, por ejemplo, el avión común (Delichon urbicum), cuya presencia indica la buena calidad del aire que respiramos.

Mientras que a nivel de flora resalta, sin lugar a dudas, la flor del hombre ahorcado (Aceras antropophorum), orquídea protegida (como 
especie vigilada) en el Catálogo Valenciano de Especies de Flora Amenazadas ${ }^{3}$.

A tenor de lo expuesto, puede apreciarse el enorme potencial del CPCC, cuya gestión global está dando, ahora, los primeros pasos.

\subsection{Del Castell de Castalla al Conjunt Patrimonial del Castell de Castalla. ¿Un cambio necesario?}

La superación del tándem patrimonio cultural igual a monumentos, aislados o incluyendo entorno y/o ambiente, y las obras de arte, a partir de la $2^{\text {a }} 1 / 2$ del siglo XX; ha permitido valorar como patrimonio cultural bienes hasta la fecha no considerados como tal, caso de los pertenecientes a las clases más humildes o a los nuevos países surgidos de la descolonización, por citar dos ejemplos. De esta manera, tal y como recoge la UNESCO en la Conferencia Mundial sobre Patrimonio Cultural (México, 1982)

"El Patrimonio Cultural de un pueblo comprende las obras de sus artistas, arquitectos, músicos, escritores y sabios, así como las creaciones anónimas, surgidas del alma popular, y el conjunto de valores que dan sentido a la vida, es decir, las obras materiales y no materiales que expresan la creatividad de ese pueblo; la lengua, los ritos, las creencias, los lugares y monumentos históricos, la literatura, las obras de arte y los archivos y bibliotecas" (http://portal.unesco.org/culture/es/files/35197/1 1919413801mexico_sp.pdf/mexico_sp.pdf).

Nos encontramos, pues, ante una diversidad patrimonial que también ha sido reconocida por las diferentes leyes autonómicas en materia de patrimonio cultural como la Ley 5/2007, de 9 de febrero, de la Generalitat, de modificación de la Ley 4/1998, de 11 de junio, del Patrimonio Cultural Valenciano, que considera patrimonio cultural: los bienes muebles e inmuebles de valor histórico, artístico, arquitectónico, arqueológico, paleontológico, etnológico, documental, bibliográfico, científico, técnico y los de cualquier otra naturaleza; las creaciones, conocimientos, técnicas, prácticas y usos más representativos y valiosos de las formas de vida y de la cultura tradicional valenciana; y las manifestaciones musicales, artísticas, gastronómicas o de ocio, especialmente las transmitidas oralmente y las que mantienen y potencian el uso del valenciano.

Se trata, en palabras de Juan Aguado Torrico (1999: 40), de un cambio terminológico y de mentalidad que todavía no ha concluido, desde un viejo modelo formado por el patrimonio histórico-artístico, caracterizado por ser restringido, elitista y centrarse y limitarse a la cultura material; a otro nuevo integrado por el patrimonio cultural, de carácter abierto, no elitista y centrarse en la cultura material e inmaterial y los bienes naturales antropizados (paisajes culturales). Así pues, este nuevo modelo exige, al menos en el plano teórico porque la realidad a veces difiere, la gestión integral de todos los bienes culturales y los naturales antropizados, sin importar su mayor o menor monumentalidad, valor o interés. Sin una administración global siempre habrá bienes abandonados, e incluso marginados a favor de otros, que, incluso, podrían llegar a desaparecer. Por lo tanto, respondiendo a la pregunta formulada en el título de este subapartado, el cambio terminológico de Castell de Castalla a Conjunt Patrimonial del Castell de Castalla, era indispensable para reconocer la verdadera realidad patrimonial, cultural y natural, del cerro del castillo. Y, así, poder gestionarla adecuadamente para conocerla, conservarla, difundirla y aprender de ella. Sin dicho cambio, habría sido difícil avanzar en esta línea porque la fortificación se seguiría viendo, desde un punto de vista social amplio, e incluso legal, como el único hito patrimonial del promontorio.

\section{Gestión}

A partir de los planteamientos expuestos, puede afirmarse que la administración del CPCC se caracteriza por ser integral. Es decir, abarca todo el patrimonio cultural, sea o no monumental o histórico-artístico, y natural presente en el cerro. En este sentido se trabaja en la línea expuesta por María Ángeles Querol Fernández (1995), sobre la necesidad de administrar conjuntamente ambos patrimonios unificando actuaciones; y 
teniendo como referentes algunos ejemplos del mundo anglosajón como el Castle Campbell (Escocia), que cuenta con diversas semejanzas al $\mathrm{CPCC}$ al encontrarse en un espacio que combina patrimonio cultural y natural.

(http://data.historic-

scotland.gov.uk/pls/htmldb/f?p=2400:15:0::::GA RDEN:GDL00089).

Su ejecución se lleva a cabo, hasta que se apruebe definitivamente el correspondiente plan director en fase de redacción; en el marco del Proyecto de recuperación social del Conjunt Patrimonial del Castell de Castalla ${ }^{4}$. Éste plan de gestión es un proyecto público puesto en marcha e impulsado, por el Ayuntamiento de Castalla en 2009 y gestionado, directamente, por la Concejalía de Patrimonio Cultural y su Servei Municipal de Patrimoni Cultural de Castalla (en adelante SMPC). En esta tarea el personal del SMPC coordina y codirige un equipo interdisciplinar (cuyo origen se encuentra en el grupo humano que inició la recuperación del Castell de Castalla en 1984), formado por 20 investigadores y profesionales del patrimonio cultural y natural. Dicho grupo humano se encarga de diseñar y ejecutar buena parte de las acciones (de investigación, conservación, restauración, didáctica y difusión), que se llevan a cabo.

En esta tarea el SMPC cuenta, además, con la colaboración estrecha de otras concejalías del Ayuntamiento (Cultura, Medio ambiente, Mantenimiento urbano y Turismo); y de centros educativos locales y científicos como la Universitat d'Alacant y la Universitat de València.

Finalmente, los recursos económicos para la redacción y ejecución de las actuaciones procede, mayoritariamente, del propio Ayuntamiento de Castalla. Pero, para determinadas intervenciones, como la restauración de las pinturas y el pavimento cerámico del camarín de la Ermita de la Sang (2011) y el acondicionamiento del aljibe de la vila de Castalla (fig. 2); ha sido fundamental la ayuda económica de la Generalitat Valenciana, a través de su Conselleria d'Educació, Cultura i Esport y la Direcció General de Cultura.

\section{Situación actual}

Aunque el arranque del CPCC no se ha producido en el mejor contexto posible, por la situación económica en la cual nos encontramos inmersos; el trabajo desarrollado, desde el año 2009 y hasta la actualidad, ha empezado a ofrecer resultados más que interesantes. No obstante, a pesar de los condicionantes económicos y la "juventud" del proyecto, puede afirmarse que en estos momentos la administración CPCC presenta una buena proyección que está permitiendo alcanzar, progresivamente, los objetivos marcados. Éstos consisten, a nivel general, en la continuación de la recuperación social del CPCC mediante la implementación de un modelo de administración profesional basado en la investigación, conservación, restauración, didáctica y difusión. Mientras que a nivel específico tratan de:

- Incrementar y mejorar el conocimiento de los bienes culturales y naturales que integran el CPCC.

- Garantizar su buen estado de conservación.

- Crear un producto cultural y turístico de calidad, que contribuya al desarrollo económico y social de Castalla.

- Favorecer el acceso y disfrute de la sociedad al patrimonio cultural de Castalla, en general, y al $\mathrm{CPCC}$ en particular.

Si se habla de actuaciones propiamente dichas, y poniendo el foco de atención, de manera amplia, en el CPCC, son muchas las ejecutadas entre 2009 y 2015 . De todas ellas se quiere destacar la delimitación del entorno del castillo y las murallas de Castalla que, si bien solo se centra en los bienes culturales materiales, ha supuesto un importante avance respecto al reconocimiento jurídico de la pluralidad patrimonial del CPCC, aunque todavía queda bastante por hacer.

Esta iniciativa, en vigor definitivo desde la aprobación definitiva del Decreto 36/2014, de 7 de marzo, del Consell, por el que se complementa la declaración de Bien de Interés Cultural del Castillo y Murallas de Castalla, sitos en el término municipal de Castalla, mediante la delimitación de su entorno de 
protección y establecimiento de su normativa de protección; ha servido para delimitar un entorno y establecer una normativa de protección del CPCC. Pero, además, ha permitido incluir, y proteger como bienes de relevancia local, en el Inventario del Patrimonio Cultural Valenciano (en adelante IPCC) bienes que hasta la fecha no lo estaban, caso del posible albacar y la necrópolis del Fossar Vell, la vila de Castalla, los depósitos de agua de 1928 y 1960 y los márgenes y bancales de cultivo tradicionales.

Por otro lado, el CPCC no es el único ejemplo en la provincia de Alicante, pues existen diversos castillos situados en cerros, o espacios similares, con una elevada riqueza y diversidad patrimonial. Un buen ejemplo lo representa el Castillo de Sax en cuya peña se localizan bienes culturales materiales (castillo, pozo de nieve, yacimiento arqueológico de la Edad del Bronce, cruz de la peña y vértice geodésico) y bienes naturales. En este sentido la peña está protegida como Paraje Natural Municipal. La principal diferencia entre ambos hitos patrimoniales (Castalla y Sax) se encuentra, en su gestión. Mientras que, en el caso del CPCC es global, la del Castillo de Sax es parcial. Es decir, no hay una administración conjunta y/o coordinada del patrimonio cultural y natural. Aunque, en principio, este hecho no significa que la gestión de Castalla sea mejor que la de Sax o viceversa.

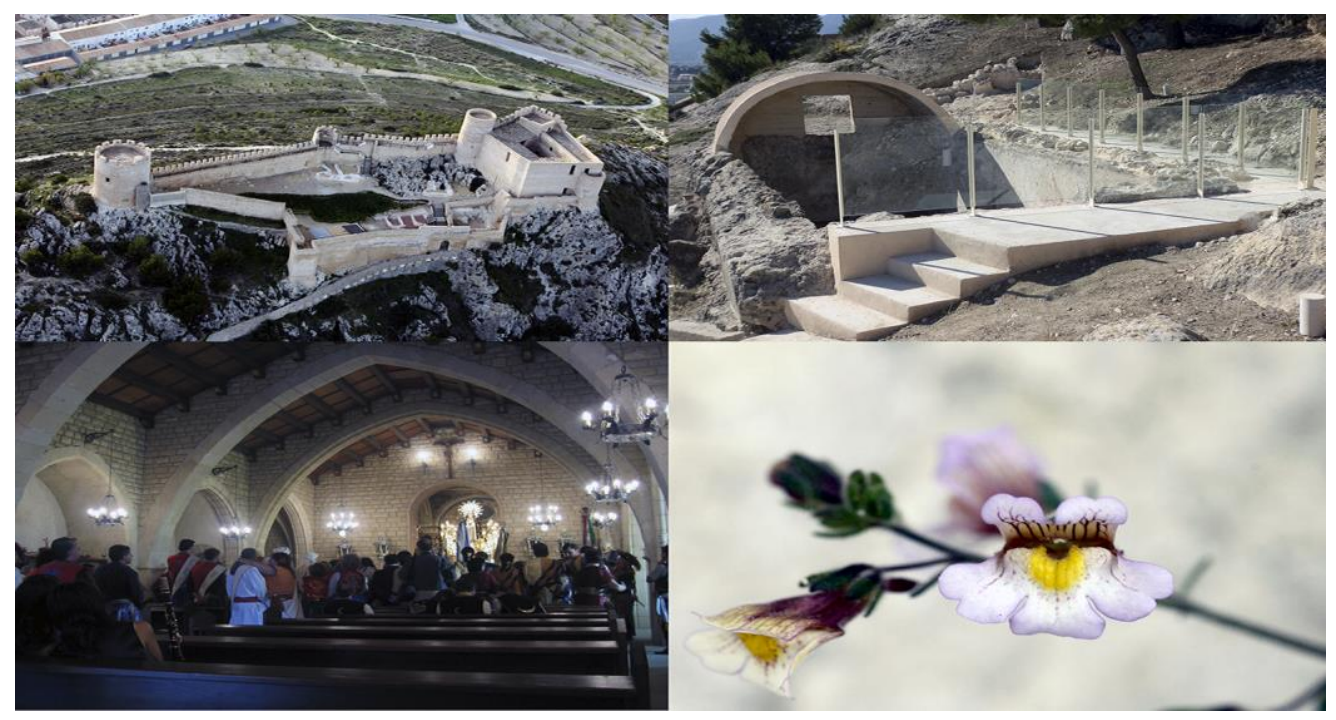

Fig. 2- Bienes culturales y naturales del Conjunt Patrimonial del Castell de Castalla: Castell de Castalla (Autor: Andrés Ruiz Sánchez), aljibe de la vila de Castalla, festividad de Sant Jaume (autor: Frederic Josep Cerdà i Bordera) y conejitos (Chaenorhinum crassifolium subs. crassifolium) (autor: D. Liñana Torres).

\section{Perspectivas de futuro}

A tenor de lo expuesto en las páginas precedentes, el CPCC se encuentra en una situación con grandes posibilidades desarrollo. No obstante, también existen peligros e incertidumbres que sólo podrán mantenerse alejados mediante el compromiso, el apoyo y la participación activa del Ayuntamiento y la población local de Castalla.
En líneas generales hay que seguir trabajando para que la gestión integral de su patrimonio cultural y natural, se plasme en un reconocimiento jurídico global del cual carece ahora mismo. En este sentido, no hay que olvidar que, si bien hay mucho patrimonio del CPCC incluido en el IPCC, y por lo tanto protegido, todavía hay otro que no se ha protegido caso, por ejemplo, del escenario bélico de las batallas de Castalla. 
Un primer intento se produjo en el transcurso del congreso Alcoy 750 aniversario del otorgamiento de la Carta Puebla (Alcoy, 2-3 de junio y 16-18 de noviembre de 2006), en el cual se apostó por la protección del CPCC como Bien de Interés Cultural con la categoría de Sitio Histórico, considerando como tal (según el artículo 26.1.A.e de la Ley 5/2007, de 9 de febrero, de la Generalitat, de modificación de la Ley 4/1998, de 11 de junio, del Patrimonio Cultural Valenciano)

"El lugar vinculado a acontecimientos del pasado, tradiciones populares, o creaciones culturales de valor histórico, etnológico o antropológico".

Se optó por esta opción porque, no sin cierto forzamiento, se consideró como la más idónea para proteger los bienes culturales materiales e inmateriales del cerro. Pues, siguiendo el esquema de José María Abad y María Buzarco (2006: 46), cumplía con los tres requisitos relacionados entre sí para la declaración de un bien como tal: existencia de un lugar, que servía de soporte para el patrimonio cultural material e inmaterial (el cerro), vinculación del lugar con algún hecho de carácter material o inmaterial (como las Fiestas de moros y cristianos); y existencia de unos valores atribuibles al lugar, relacionado con un supuesto o hecho material o inmaterial.

El tiempo transcurrido desde esta primera formulación, la inclusión del patrimonio natural en la gestión del CPCC, así como los avances producidos por la investigación; permiten ahora mejorar la propuesta inicial. En este sentido, y tomando, nuevamente, como marco de referencia el artículo 26.1.A.h de la Ley 5/2007, de 9 de febrero, de la Generalitat, de modificación de la Ley 4/1998, de 11 de junio, del Patrimonio Cultural Valenciano; se apuesta por la protección del CPCC como Bien de Interés Cultural, con la categoría de Parque Cultural, entendiendo por tal

"El espacio que contiene elementos significativos del patrimonio cultural integrados en un medio físico relevante por sus valores paisajísticos y ecológicos".
Como se ve en su propia definición, la figura de Parque Cultural permite proteger todo el patrimonio cultural material e inmaterial situado en el cerro y también menciona el patrimonio natural. No obstante, aunque el patrimonio natural no se proteja, pues no hay que olvidar que se trata de una figura procedente de la legislación en materia de patrimonio cultural; esta declaración puede complementarse con una figura de protección a nivel medioambiental como, por ejemplo, la de Paraje Natural Municipal o la de Monumento Natural ${ }^{5}$.

Además, todo este proceso debe incluirse dentro de un documento marco que defina la estrategia a seguir para conseguir, no solo el reconocimiento jurídico global del CPCC, sino su recuperación social a corto, medio y largo plazo. En esta línea la apuesta se centra en la redacción del Plan director para la recuperación social del Conjunt Patrimonial del Castell de Castalla. Una herramienta, flexible y adaptable a los cambios e imprevistos y destinada a sustituir al actual plan de gestión, que ahora mismo se encuentra en proceso de diseño bajo la dirección de los autores del presente trabajo. Sin ánimo de ser exhaustivos, y de modo genérico, este documento deberá sentar las bases para:

- Abordar la musealización del Castell de Castalla, previa redacción del proyecto correspondiente. En estos momentos la fortificación es un gran continente sin contenido. Este hecho debe ser corregido para conocer mejor su historia, así como potenciar y completar, definitivamente, su conversión en un producto turístico-cultural.

- Continuar con las intervenciones en el resto de bienes culturales y naturales que forman el CPCC. Aquí es prioritario finalizar el inventario de fauna y flora incluyendo la fauna invertebrada, así como confirmar o descartar la existencia de la necrópolis del Fossar Vell o determinar si el albacar es tal o se trata de otro tipo de estructura.

- Incluir el CPCC en el Plan General de Ordenación Urbana de Castalla y en su Catálogo de Bienes y Espacios. 
- Continuar y aumentar la colaboración con los centros educativos y formativos locales y con la Universidad de Alicante, centro científico, cultural y educativo de referencia en la provincia de Alicante.

- Convertir el CPCC en un espacio público. En la actualidad la propiedad del CPCC se reparte entre el Ayuntamiento de Castalla, que posee la mayor parte, y diversos propietarios privados. Para una mejor gestión del espacio es necesario que la corporación municipal incorpore, progresivamente, las parcelas privadas al domino público.

- Establecer sinergias con otros hitos patrimoniales similares, así como con otros castillos de la provincia. Especialmente con los de la Ruta de los Castillos del Vinalopó (http://www.rutacastillosvinalopo.net), de la cual forman parte el Castell de Castalla y el Castillo de Sax, cuyas semejanzas y complementariedad (fortificaciones próximas pero pertenecientes a coronas distintas durante buena parte de la Edad Media), permitiría ejecutar interesantes acciones conjuntas. Como, por ejemplo, visitas guiadas que expliquen aspectos comunes y diferentes de ambos castillos.

\section{Notas}

(1) La presente comunicación forma parte de la tesis doctoral de J. A. Mira Rico, en curso en el momento de redactar este trabajo, que analiza la gestión que los municipios de la provincia de Alicante realizan de los castillos que son de su propiedad. La misma se desarrolla en el seno del Área de Prehistoria de la Universidad de Alicante.

(2) Más información en http://www.cma.gva.es/web/indice.aspx?nodo=5 5853\&idioma $=$ C.

(3) Se utiliza la denominación tradicional en valenciano.

(4) Más información en http://www.gestioncultural.org/buenas_practicas .php?id_proyectos=299223.

(5) Más información en http://www.citma.gva.es/web/parajes-naturalesmunicipales/presentacion y http://www.citma.gva.es/web/espaciosprotegidos/monumentos-naturales

\section{Referencias}

Abad, J. Mª, Buzarco, M ${ }^{\mathrm{a}}$. (2006). Patrimonio cultural. Los sitios históricos de interés militar. Dyikinson, S.L. Ed. Madrid. p. 488.

Agudo, J. (1999). "Cultura, patrimonio etnológico e identidad" in Boletín de Patrimonio Histórico. Instituto Andaluz de Patrimonio Histórico Ed. Sevilla. pp. 36-45.

Ariño, A. (1988). Festes, Rituals i Creences. Alfons el Magnànim. Ed. València. p. 261.

Ariño, A., Alcaraz, A. (2001). "Moros y Cristianos" in Calendario de Fiestas de Verano de la Comunidad Valenciana. Valencia. Fundación Bancaja Ed. Valencia. pp. 14-37.

Ariño, A., Hernández, G. M., Melis, A. (1999). "El Ciclo Pascual" in Calendario de Fiestas de Primavera de la Comunidad Valenciana. Fundación Bancaja Ed. Valencia. pp. 59-87.

Bevià, M., Camarero, E., Jiménez. P. (1985) Informe previo del Castell de Castalla. Unreleased.

Cerdà, F. J. (1994). "El II mil·lenni a la Foia de Castalla (Alacant): Excavacions a la Foia de la Perera (Castalla)" in Recerques del Museu d'Alcoi. Museu d'Alcoi Ed. Alcoi. pp. 95-110.

Cerdà F. J., Espinosa J.M". (2008). "Castalla i el context històric: 1858-2008” in Comparsa dels Moros Grocs. 150 aniversari. 1858-2008. Comparsa dels Moros Grocs Ed. Castalla. pp. 9-247.

González, M. Á. (2004). Castalla y Onil en el origen de la fiesta de moros y cristianos (1473-1804). Agrupació de Comparses de Moros i Cristians de Castalla y Diputación de Alicante. Ed. Alicante. p. 201.

González, M. Á. (2010). "De castillos y guerrilleros. Las milicias de voluntarios honrados de la Foia de Castalla en la Guerra de Independencia (1812-1813)" in El Castell de Castalla. Arqueología, arquitectura e historia de una fortificación medieval de frontera. MARQ Ed. Alicante. pp. 255-265. Llop, F. (2011). Informe sobre la campana de l'ermita de la Sang de Castalla. Unreleased. 
Marco, J. A. (1987). El macizo del Maigmó. Estudio de geografia física. Instituto Alicantino de Cultura Juan Gil-Albert Ed. Alicante. p. 171.

Menéndez, J. L., Bevià, M., Mira, J. A., Ortega, J. R. (2010). El Castell de Castalla. Arqueología, arquitectura e historia de una fortificación de frontera. MARQ Ed. Alicante. p. 309.

Mira, J. A. (2005). La gestión sostenible del patrimonio: propuestas de revalorización del patrimonio arqueológico del municipio de Castalla (Alicante). Unreleased.

Mira, J. A. (in press). "El Conjunt Patrimonial del Castell de Castalla: definición, gestión situación actual y perspectivas de futuro de un proyecto interdisciplinar de carácter local" in Actas del seminario Una frontera medieval. Castalla i el sud del regne de València (segles XIII-XV). Commemoració del 700 i 725 aniversari de la concessió de mercat setmanal $i$ la carta pobla a Castalla (24-26 de novembre de 2011 i 27 de gener de 2012).

Mira, J. A., Liñana, D. (2014). El Conjunt Patrimonial del Castell de Castalla. Una porta oberta cap al patrimoni natural. Guia de visita de fauna i flora. Ajuntament de Castalla Ed. Castalla. p. 24.

Mira, J. A., Ortega, J. R. (2010). "Proyecto de alzamiento topográfico de las estructuras exteriores al recinto superior del Castell de Castalla (Castalla, Alicante)" in Actuaciones arqueológicas en la provincia de Alicante 2009. Sección de Arqueología del Colegio Oficial de Doctores y Licenciados en Filosofía y Letras y Ciencias de Alicante Ed. Alicante. Documento en cd-rom.

Ortega, J. R., Esquembre. M. A. (2010). "Intervención arqueológica en el interior del recinto fortificado del Castell de Castalla" in El Castell de Castalla. Arqueología, arquitectura e historia de una fortificación medieval de frontera. MARQ Ed. Alicante. pp. 61-106.

Querol Má. Á. (1995). “Patrimonio cultural y patrimonio natural: ¿una pareja imposible?”. Extremadura arqueológica. Universidad de Extremadura Ed. Mérida. pp. 301-306.

Torró, J. (1988-1989). "El problema del hábitat fortificado en el sur del Reino de Valencia después de la segunda revuelta mudéjar (1276-1304)" in Anales de la Universidad de Alicante. Historia Medieval. Universidad de Alicante Ed. Alicante. pp. 53-82.

Vidal, I., Navarro, R. (1985). "Arte Medieval" in Historia de la Provincia de Alicante. Ed. Mediterráneo, Murcia, pp. 441-477. 